\title{
Pregnancy and delivery outcomes of HIV infected women in Switzerland 2003-2008
}

\author{
Karoline Aebi-Popp ${ }^{1, *}$, Olav Lapaire ${ }^{1}$, Tracy R. \\ Glass $^{2}$, Louise Vilén ${ }^{3}$, Christoph Rudin ${ }^{4}$, Luigia Elzi ${ }^{5}$, \\ Mannel Battegay ${ }^{5}$, Olivia Keiser ${ }^{6}$, Begona Martinez \\ de Tejada ${ }^{7}$, Irene M. Hoesli ${ }^{1}$ and The Swiss Mother \\ and Child HIV Cohort Study \\ ${ }^{1}$ Division of Obstetrics and Gynaecology, University \\ Hospital Basel, Switzerland \\ ${ }^{2}$ Basel Institute for Clinical Epidemiology and \\ Biostatistics, University Hospital Basel, Switzerland \\ ${ }^{3}$ Institute for Psychology, University Bern, Switzerland \\ ${ }^{4}$ Division of Infectious Diseases, University Children's \\ Hospital, Basel, Switzerland \\ ${ }^{5}$ Division of Infectious Diseases and Hospital \\ Epidemiology, University Hospital Basel, Switzerland \\ ${ }^{6}$ Institute for Social and Preventive Medicine, Bern, \\ Switzerland \\ ${ }^{7}$ Division of Obstetrics and Gynaecology, University \\ Hospital Geneva, Switzerland
}

\begin{abstract} eclampsia and gestational diabetes mellitus.

*Corresponding author:

K. Aebi-Popp, MD

Department of Obstetrics and Gynaecology

University Hospital Basel

Spitalstrasse 21

CH-4031 Basel

Switzerland

Tel.: +41612652525

Fax: +41612659198

E-mail: kaebi@uhbs.ch
\end{abstract}

Objective: Rates of vertical HIV transmission between mother and child are low, allowing many HIV positive women to have children with near impunity. In this study, data from the Swiss Mother and Child HIV Cohort Study were used to describe maternal characteristics and their association with pregnancy outcomes in HIV positive women.

Study design: HIV positive women were followed prospectively during their pregnancies and deliveries by anonymous questionnaires between January 2003 and October 2008. Adverse pregnancy outcomes included preterm delivery, pre-

Results: This study included 266 HIV positive women, of which 67 (25.2\%) were first diagnosed with HIV during pregnancy. Thirty percent $(n=80)$ of the women had pregnancy complications after 24 weeks of gestation. Preterm delivery was noted in $72(27 \%)$ patients. Other complications included preeclampsia $(\mathrm{n}=7 ; 2.6 \%)$ and gestational diabetes $(\mathrm{n}=7 ; 2.6 \%)$. Older maternal age was the only risk factor associated with adverse pregnancy outcomes (adjusted odds ratio: $1.06,95 \%$ confidence interval $1.01-1.12, \mathrm{P}=0.02$ ).

Conclusions: HIV positive women, especially with advanced maternal age, have high-risk pregnancies and should be monitored as in an interdisciplinary setting. The preponderance of initial HIV diagnosis during pregnancy confirms the importance of HIV screening in pregnant women.

Keywords: HIV; maternal age; pregnancy; preterm delivery.

\section{Introduction}

Heterosexual women of childbearing age represent the fastest growing risk-group for HIV infection [33] and several studies have shown an increasing prevalence of HIV infection in European women in their reproductive years [12]. Meanwhile, the widespread use of combined antiretroviral treatment (cART) among HIV infected women has led to a dramatic decrease in the rate of mother-to-child transmission (MTCT) in Europe to around 1\% [1, 5, 10, 11]. Because of cART therapy, HIV positive people can live healthier lives with almost normal life expectancies. This reinforces the desire of HIV positive women to have their own children and plan their pregnancies. However, HIV positive women are still confronted with the fear of vertical transmission of HIV as well as the possible risk of an adverse pregnancy outcome namely, preterm delivery, preeclampsia or gestational diabetes. Little is known regarding prevalence and maternal risk factors of adverse pregnancy outcomes in HIV positive women. Some authors reported an increased risk of preterm delivery, particularly if a regimen containing protease inhibitors is administered before and during pregnancy [adjusted odds ratio (aOR) 2.6] [1, 7, 18]. Many studies addressing pregnancy in HIV positive women focus mainly on the type of antiretroviral therapy (ART) administered $[4,9,13,19,30]$.

However, maternal age, ethnicity, smoking habits, coinfections and obesity may influence pregnancy outcome in HIV negative women [17, 20, 21, 28, 32]. The goal of the present study was therefore to analyse maternal characteristics and delivery outcomes of HIV positive women who seek prenatal treatment in Switzerland. We hypothesised that maternal characteristics and co-morbidities do influence pregnancy outcome, even under optimal ART. 


\section{Methods}

The Swiss Mother and Child HIV Cohort Study (MoCHiV) is an ongoing prospective observational study. In 2003, MoCHiV was fully integrated into the Swiss HIV Cohort Study (SHCS) and new questionnaires were introduced, containing more information about maternal characteristics, pregnancy and delivery complications. The anonymously collected data include demographic information, clinical and medical history as well as follow-up data. Written informed consent was obtained in all cases and ethical approval for the study was granted.

All pregnant women enrolled in the SHCS between January 2003 and October 2008 who agreed to participate in MoCHiV were included in the study. Maternal information included results of clinical and laboratory investigations, information about ART, intravenous drug abuse, alcohol abuse, smoking habits and sociodemographic information. Gestational age was defined as the time between the first day of the last menstrual period and the day of delivery. Preterm delivery was defined as duration of pregnancy between 34 weeks +0 days and 37 weeks +0 days of gestation and very preterm delivery between $24+0$ and $34+0$ weeks' gestation.

A shortened cervix was defined as a cervical length $<25 \mathrm{~mm}$, measured by transvaginal ultrasound. Intrauterine growth retardation (IUGR) was defined as an estimated fetal weight under the $5^{\text {th }}$ percentile as measured by transabdominal ultrasound. Maternal CD4+ cell counts (cells/ $\mu \mathrm{L}$ ) and HIV RNA level (RNA-copies/mL) nearest to the time of delivery were used in the analyses. CD $4+$ cell counts were categorised as <200, 200-499 and >500 cells/ $\mu \mathrm{L}$. Screening for gestational diabetes mellitus was performed between 24 and 28 weeks' gestation with a 50-g glucose challenge test. Caesarean section before the onset of labour and rupture of membranes was categorized as elective and all others as secondary/emergency. In this period of the study, women were offered an elective caesarean section according to the Swiss guidelines. Vaginal delivery was offered in some centres since 2006 for women with undetectable viral load and without co-infections. Newborns were tested for HIV at one and six months after delivery with two different tests (antigen p24 and DNA PCR) at each time. Once all tests were found to be negative, the child was considered as non-infected.

Categorical data were analysed by calculating percentages and $\chi^{2}$-tests. Means, medians, standard deviations (SD), and interquartile ranges (IQR) were calculated for continuous variables. Multivariable logistic regression was used to study the association between maternal factors and adverse pregnancy outcome. Adverse pregnancy outcome was defined as occurrence of any of the following conditions: preterm delivery, cervical shortening, premature rupture of membranes (PROM), preeclampsia or arterial hypertension, vaginal bleeding and gestational diabetes. Explanatory variables included in the model were ethnicity (Caucasian vs. non-Caucasian), maternal cigarette smoking, drug use, co-infections (hepatitis B, hepatitis $\mathrm{C}$, syphilis), maternal BMI, cART regimen, $\mathrm{CD} 4+$ cell count, duration of HIV infection and maternal age. Time varying variables were included at the time of conception if not otherwise stated. $\mathrm{P}<0.05$ were defined as statistically significant.

\section{Results}

Overall, 269 pregnancies were reported to the SHCS of which 266 were also included into MoCHiV. Thus data were available for 266 mother-child pairs. In total, 261 women $(98.1 \%)$ had singleton pregnancies, five $(1.9 \%)$ had twin gestations, of which two pairs were monochorionic and three
Table 1 Maternal characteristics.

\begin{tabular}{|c|c|}
\hline Characteristic & Value $(n=266)$ \\
\hline Maternal age at delivery, mean (SD) & $32(5.4)$ \\
\hline \multicolumn{2}{|l|}{ Ethnicity, n (\%) } \\
\hline Caucasian & $92(34.6)$ \\
\hline Non-White & $174(65.4)$ \\
\hline \multicolumn{2}{|l|}{ Mode of acquisition, n (\%) } \\
\hline Heterosexual sex & $226(85.0)$ \\
\hline Injection drug use & $29(10.9)$ \\
\hline Other & $11(4.1)$ \\
\hline HIV diagnosis during pregnancy, $\mathrm{n}(\%)$ & $67(25.2)$ \\
\hline $\begin{array}{l}\text { Time since positive HIV-test (years), median } \\
\text { (IQR) }\end{array}$ & $5.2(2.7-9.6)$ \\
\hline \multicolumn{2}{|l|}{$\begin{array}{l}\text { HIV-1 RNA viral load at delivery (copies/mL), } \\
\mathrm{n} / 244(\%)\end{array}$} \\
\hline$<50$ & $192(78.7)$ \\
\hline $50-399$ & $33(13.5)$ \\
\hline$\geq 400$ & $19(7.8)$ \\
\hline \multicolumn{2}{|l|}{ CD4 cell count at delivery (cells/ $\mu \mathrm{L}), \mathrm{n} / 210(\%)$} \\
\hline$<200$ & $15(7.1)$ \\
\hline $200-349$ & $63(30.0)$ \\
\hline$\geq 350$ & $132(62.9)$ \\
\hline \multicolumn{2}{|l|}{ ART naive, n (\%) } \\
\hline At conception & $94(35.5)$ \\
\hline At delivery & $5(1.9)$ \\
\hline \multicolumn{2}{|l|}{ Type of conception, n (\%) } \\
\hline Spontaneous & $235(88.3)$ \\
\hline Infertility treatment & $3(1.1)$ \\
\hline Artificial insemination & $2(0.8)$ \\
\hline Self insemination & $16(6.0)$ \\
\hline Unknown & $10(3.8)$ \\
\hline \multicolumn{2}{|l|}{ Mode of delivery } \\
\hline \multicolumn{2}{|l|}{ Caesarean section } \\
\hline Elective & $180(67.7)$ \\
\hline Secondary & $56(21.1)$ \\
\hline \multicolumn{2}{|l|}{ Vaginal } \\
\hline Spontaneous & $21(7.9)$ \\
\hline Instrumental & $7(2.6)$ \\
\hline \multicolumn{2}{|l|}{ Duration of pregnancy, n (\%) } \\
\hline$<37$ weeks & $72(27.1)$ \\
\hline$>37$ weeks & $194(73.0)$ \\
\hline
\end{tabular}

$\mathrm{SD}=$ standard deviation, $\mathrm{IQR}=$ interquartile range, $\mathrm{ART}=$ antiretroviral therapy.

were dichorionic. In 226 women (85\%) the HIV infection was heterosexually acquired, $29(20.9 \%)$ were infected via intravenous drug use and in $11(4.9 \%)$ the aetiology was unknown (Table 1). Type of conception was reported for all 266 pregnancies. Of these, 235 (91.1\%) conceptions were spontaneous, with no protective having been used, and the HIV status of the partner is unknown in this data set. Five pregnancies $(2 \%)$ were achieved through infertility treatment and $16(6.2 \%)$ by artificial (homologous)-insemination. The mean maternal age of women at their first prenatal visit was 32 (SD: 5.4) years. Women presented at a median gestational age of 12.3 weeks for the first prenatal visit with a wide range from 6 to 40 weeks. Cigarette smoking during pregnancy was reported by 49 women $(18.4 \%)$, alcohol abuse by 22 women $(8.3 \%)$ and intravenous drug abuse by 16 women $(6.0 \%)$. Ten $(3.8 \%)$ women were diagnosed with a hepatitis 
Table 2 Maternal characteristics according to duration of pregnancy.

\begin{tabular}{|c|c|c|c|}
\hline & \multicolumn{3}{|c|}{ Duration of pregnancy in weeks } \\
\hline & $\begin{array}{l}24+0 \text { to } 33+6 \\
\mathrm{n}=19\end{array}$ & $\begin{array}{l}34+0 \text { to } 36+6 \\
n=53\end{array}$ & $\begin{array}{l}>37 \\
\mathrm{n}=194\end{array}$ \\
\hline Age at delivery (years), mean (SD) & $33.3(3.7)$ & $33.7(5.1)$ & $31.6(5.7)$ \\
\hline Non-White ethnicity, n (\%) & $137(68.4)$ & $35(66.0)$ & $126(65.0)$ \\
\hline \multicolumn{4}{|l|}{ BMI $\left(\mathrm{kg} / \mathrm{m}^{2}\right), \mathrm{n}(\%)$} \\
\hline$\leq 18$ & $0(0)$ & $0(0)$ & $1(0.5)$ \\
\hline $19-30$ & $11(57.9)$ & $46(86.8)$ & $154(79.4)$ \\
\hline$>30$ & $4(21.1)$ & $5(9.4)$ & $21(10.8)$ \\
\hline \multicolumn{4}{|l|}{ Risk group for HIV infection, $\mathrm{n}(\%)$} \\
\hline Heterosexual & $15(78.9)$ & $49(92.5)$ & $162(83.5)$ \\
\hline IV drug & $3(15.8)$ & $3(5.7)$ & $23(11.9)$ \\
\hline Other & $1(5.3)$ & $1(1.9)$ & $8(4.1)$ \\
\hline Smoking during pregnancy, n (\%) & $2(10.5)$ & $10(18.7)$ & $37(19.1)$ \\
\hline Drug use during pregnancy, n (\%) & $1(5.3)$ & $4(7.5)$ & $11(5.7)$ \\
\hline Any alcohol consumption, $\mathrm{n}(\%)$ & $4(21.1)$ & $3(5.7)$ & $15(7.7)$ \\
\hline \multicolumn{4}{|l|}{ Co-infection, n $(\%)$} \\
\hline Hep B (positive Ag-HBs test) & $1(5.3)$ & $0(0)$ & $9(4.6)$ \\
\hline Hep C (positive Anti-HCV test) & $2(10.5)$ & $2(3.8)$ & $6(3.1)$ \\
\hline Syphilis (positive TPHA or TPPA) & $1(5.3)$ & $0(0)$ & $3(1.5)$ \\
\hline \multicolumn{4}{|l|}{ Type of conception $(\%)$} \\
\hline Spontaneous & $18(94.7)$ & $47(88.7)$ & $170(87.6)$ \\
\hline Infertility treatment & $0(0)$ & $2(3.8)$ & $1(0.5)$ \\
\hline Artificial insemination & $0(0)$ & $0(0)$ & $2(1.0)$ \\
\hline Self insemination & $0(0)$ & $2(3.8)$ & $14(7.2)$ \\
\hline \multicolumn{4}{|l|}{ Gestational age in weeks at $1^{\text {st }}$ GYN visit } \\
\hline Mean (SD) & $11.1(5.4)$ & $11.5(6.0)$ & $13.1(7.1)$ \\
\hline Median (IQR) & $10.6(6-25)$ & $9.9(7-12)$ & $11.4(5-40)$ \\
\hline \multicolumn{4}{|l|}{ HIV-RNA viral load (copies/mL), $\mathrm{n}=244(\%)$} \\
\hline$<50$ & $13(68.4)$ & $33(70.2)$ & $146(81.6)$ \\
\hline $50-399$ & $4(21.1)$ & $8(17.0)$ & $21(11.7)$ \\
\hline$\geq 400$ & $1(5.3)$ & $6(12.8)$ & $12(6.7)$ \\
\hline \multicolumn{4}{|l|}{$\mathrm{CD} 4$ cell count $($ cells $/ \mu \mathrm{L}) \mathrm{n}=210(\%)$} \\
\hline$<200$ & $3(15.8)$ & $2(5)$ & $10(6.3)$ \\
\hline $200-349$ & $3(15.8)$ & $12(30)$ & $48(30)$ \\
\hline $350-499$ & $2(10.5)$ & $10(25)$ & $46(28.8)$ \\
\hline$\geq 500$ & $2(10.5)$ & $16(40)$ & $56(35)$ \\
\hline HIV diagnosis prior to pregnancy, $\mathrm{n}(\%)$ & $15(78.9)$ & $45(84.9)$ & 139 (71.6) \\
\hline During current pregnancy & $4(21.1)$ & $8(15.1)$ & $55(28.4)$ \\
\hline \multicolumn{4}{|l|}{ Time living with HIV (years) } \\
\hline Median (IQR) & $8.3(2.8-14.5)$ & $4.9(2.4-7.9)$ & $4.9(2.4-9.6)$ \\
\hline \multicolumn{4}{|l|}{ ART naive, n (\%) } \\
\hline At conception & $8(42.1)$ & $17(32.1)$ & $69(26.2)$ \\
\hline At delivery & $0(0)$ & $2(3.8)$ & $3(1.6)$ \\
\hline \multicolumn{4}{|l|}{ ART class at time of delivery } \\
\hline NNRTI & $3(15.8)$ & $5(9.4)$ & $16(8.2)$ \\
\hline PI non-boosted & $3(15.8)$ & $7(13.2)$ & $40(20.6)$ \\
\hline PI boosted & $11(57.9)$ & $26(49.1)$ & $89(45.9)$ \\
\hline Triple nucleoside/other & $0(0)$ & $4(7.5)$ & $18(9.3)$ \\
\hline Off treatment & $2(105)$ & $9(17.0)$ & $25(12.9)$ \\
\hline Stopped ART during pregnancy, n (\%) & $4(21.1)$ & $18(34.0)$ & $74(38.1)$ \\
\hline \multicolumn{4}{|l|}{ Reasons for stopping ART } \\
\hline Treatment failure & $0(0)$ & $1(1.9)$ & $6(3.1)$ \\
\hline Toxicity & $0(0)$ & $3(5.7)$ & $11(5.7)$ \\
\hline Patient wish & $0(0)$ & $2(3.8)$ & $8(4.1)$ \\
\hline Doctor decision & $2(10.5)$ & $7(13.2)$ & $26(13.4)$ \\
\hline Structured treatment interruption & $0(0)$ & $2(3.8)$ & $3(1.6)$ \\
\hline Other & $2(10.5)$ & $3(5.7)$ & $15(7.7)$ \\
\hline
\end{tabular}

$\mathrm{SD}=$ standard deviation, Hep B = hepatitis B, Hep C = hepatitis C, TPHA = treponema-pallidum-hemagglutination-assay, IQR =interquartile range, $\mathrm{ART}=$ antiretroviral therapy; NNRTI $=$ non-nucleoside reverse transcriptase inhibitor. 
Table 3 Pregnancy complications after 24 weeks.

\begin{tabular}{lr}
\hline Complications after 24 weeks, $\mathrm{n}=80(30.1 \%)$ & \\
Preterm contractions, $\mathrm{n}(\%)$ & $42(15.8)$ \\
Cervical shortening, $\mathrm{n}(\%)$ & $27(10.2)$ \\
Premature rupture of membranes, $\mathrm{n}(\%)$ & $16(6.2)$ \\
Vaginal bleeding, $\mathrm{n}(\%)$ & $7(2.6)$ \\
Intrauterine growth retardation, $\mathrm{n}(\%)$ & $11(4.1)$ \\
Preeclampsia or hypertension, $\mathrm{n}(\%)$ & $7(2.6)$ \\
Gestational diabetes, $\mathrm{n}(\%)$ & $7(2.6)$ \\
Administered drugs and cerclage & \\
Antibiotics, $\mathrm{n}(\%)$ & $75(28.4)$ \\
Corticosteroids, n $(\%)$ & $27(10.4)$ \\
Tocolysis, $\mathrm{n}(\%)$ & $29(11.4)$ \\
Cerclage, $\mathrm{n}(\%)$ & $5(2.0)$ \\
\hline
\end{tabular}

B co-infection, 10 (3.8\%) women with hepatitis C co-infection and four $(1.5 \%)$ tested positive for syphilis using treponema-pallidum-hemagglutination-assay (TPHA) screening. Results from the first positive HIV test were available for all 266 women. In 199 (74.8\%) women, HIV was diagnosed prior to pregnancy. In 67 women (25.2\%), HIV infection was diagnosed during the current pregnancy. Diagnosis of HIV after conception was much more common among non-Caucasian women $(83.6 \%)$ compared to Caucasian women $(16.4 \%)(\mathrm{P}<0.01)$. At time of conception, women in the study group had HIV for a mean of 4.9 years (IQR: 2.4-9.9) and some cultural differences were noticeable. Non-Caucasians had been diagnosed with HIV for an average of 3.1 years prior to conception compared to 8.4 years for Caucasians $(\mathrm{P}<0.01)$. This difference remained significant even after controlling for maternal age.

The majority of women [251 (94.4\%)] received ART during pregnancy. Of those, 172 women $(68.5 \%)$ were already on ART prior to pregnancy. In 94 cases (35.5\%), treatment was started during pregnancy irrespective of CD4 + cell count in order to prevent vertical transmission (goal of an undetectable viral load four weeks before the date of delivery); treatment was initiated mostly in the second trimester $(\mathrm{n}=63,67.0 \%)$ at a median gestational age of 21.6 weeks (IQR 17.5-26.8 weeks). The most common cART regimen included a boosted protease inhibitor $[\mathrm{n}=126(50.2 \%)]$. It was documented that 96 women (38.2\%) intermittently discontinued ART at least once during pregnancy. The reasons are shown in Table 2. Overall, only five women (1.9\%) were not on ART at the time of delivery.
The median gestational age at birth was 37.8 (IQR 36.9-38.6) weeks or 265 days of gestation. The median birth weight was $2810 \mathrm{~g}$ (SD: 569). None of the children was infected with HIV. Intrapartum intravenous zidovudine (AZT) prophylaxis was applied during $73.9 \%$ of all deliveries and $122(93.1 \%)$ of all women continued their AZT containing ART at specific intervals at time of delivery. In the majority of the study population (192 women, 78.7\%) viral load at delivery was found to be $<50 \mathrm{RNA}$-copies $/ \mathrm{mL}$. Viral load was between 50 and 399 RNA-copies $/ \mathrm{mL}$ in 33 $(13.5 \%)$ and $>400$ RNA-copies/mL in only 19 cases (7.8\%). The CD4+ cell count at delivery was reported to be $>500$ cells $/ \mu \mathrm{L}$ in $74(35.2 \%)$ women and $<200$ cells $/ \mu \mathrm{L}$ in $15(7.1 \%)$ patients.

Twenty-eight of 266 women (10.5\%) had a vaginal delivery including 21 spontaneous deliveries, six vacuums and one forceps extraction whereas $236(88.7 \%)$ women delivered by caesarean section. In 180 cases $(67.7 \%)$ the caesarean section was elective, including eight caesarean sections before 37 weeks' gestation. Secondary caesarean section was performed in 56 cases $(21.1 \%)$ in an effort to prevent MTCT after PROM $(n=16)$ or preterm labour $(n=40)$. In all women undergoing vaginal deliveries, the HIV RNA viral load was $<50$ copies $/ \mathrm{mL}$.

Overall, 80 (30.1\%) pregnancy-related complications were reported after 24 weeks of gestation. The preterm delivery rate was high with $72(27.1 \%)$ women delivering before $37+0$ weeks' gestation; 19 women $(7.1 \%)$ delivered before 34 weeks, of these three delivered before 30 weeks. Fiftythree $(19.9 \%)$ women delivered between 34 and $36+6$ weeks (Table 3), of these eight (3\%) were elective caesarean sections without obstetrical problems. There were five twin gestations: one delivered at 31 weeks, and four delivered between 34 and 37 weeks by caesarean section. Singleton preterm delivery rate was therefore $25.7 \%$ (67/261).

Preterm contractions were found in 42 cases $(15.8 \%)$, cervical shortening in $27(10.2 \%)$ and PROM in $16(6.0 \%)$ (Table 3). Women with preterm delivery had lower CD4+ cell counts than women who delivered at term $(66.7 \%$ vs. $53.4 \%<500 / \mu \mathrm{L} ; \mathrm{P}=0.02$ ).

The multivariable analysis for risk factors for adverse pregnancy events (mainly preterm) after 24 weeks found no difference for ethnicity, smoking habits, drug use and coinfections (Table 4). Advanced maternal age was a significant risk factor for adverse pregnancy outcome even after adjusting for potential confounders like co-infections, BMI,

Table 4 Risk factors for pregnancy complications after 24 weeks, multivariate analysis.

\begin{tabular}{llll}
\hline & Odds ratio & $95 \%$ CI & P-value \\
\hline Maternal age (per 1 year increase) & 1.08 & $1.02-1.15$ & 0.01 \\
Non-White ethnicity & 0.94 & $0.44-1.99$ & 0.87 \\
Smoking during pregnancy & 0.59 & $0.22-1.56$ & 0.28 \\
Drugs during pregnancy & 1.71 & $0.45-6.45$ & 0.43 \\
Any co-infection* & 0.72 & $0.27-1.92$ & 0.51 \\
\hline
\end{tabular}

*Hepatitis B, hepatitis $\mathrm{C}$, syphilis.

$\mathrm{CI}=$ confidence interval. 
smoking habits, alcohol or drug abuse [aOR: 1.06, 95\% confidence interval (CI) 1.01-1.12, $\mathrm{P}=0.02]$.

\section{Discussion}

In the current study, the diagnosis of HIV infection was established during pregnancy in one out of four women (25.2\%). Similar rates of HIV diagnosis during pregnancy were reported from other countries, including a rate of $22 \%$ in Spain and 34\% in Germany $[10,11]$. This reinforces the need of universal HIV screening in pregnant women and those seeking pregnancy - as proposed in the national Swiss guidelines [24]. Additionally, universal screening is cost-effective in different settings [25] and should be employed with the "opt out" strategy of testing all pregnant women unless they explicitly refuse testing. Nevertheless, women first diagnosed with HIV during pregnancy require post-test counseling and treatment using a multidisciplinary approach. Generally, women at risk should be tested for HIV prior to conception; if seropositive, they should be advised to conceive once their viral load is controlled in order to protect their seronegative partners. Of note, nearly $90 \%$ of the women in our cohort conceived after unprotected sexual intercourse. Further, it has been described that women with HIV risk unprotected intercourse and delay disclosure in their relationships with the intention of becoming pregnant [26].

In our cohort, ART during pregnancy offered good antiviral control of maternal HIV infection with an undetectable viral load in $78.7 \%$ of all women at time of delivery. The majority of women, who were treatment naive at time of conception, started their therapy in the second trimester $(67.0 \%)$, and $31(33.0 \%)$ started only in the third trimester. AZT was the principal prescribed nucleoside reverse transcriptase inhibitor during pregnancy and was used in $93.1 \%$ of cases. In the recent Swiss guidelines, it is not an essential part of cART during pregnancy [24].

Compared to other studies [7, 14, 29], we did not find an increased risk of adverse pregnancy outcome including preeclampsia, hypertension or gestational diabetes in HIV positive women. However, the preterm delivery rate in the Swiss cohort was high (27\%). This rate is comparable to preterm rates of HIV infected women in Spain $(29 \%)$ and in the US $(28.9 \%)$ [8, 19]. In our cohort, women delivering preterm were of older maternal age, a risk factor known in HIV negative women $[6,23]$ and recently shown in a study of HIV positive women [3]. Eight out of 266 women had a caesarean section before 37 weeks of gestation without obvious indication. Whether the decision to perform a caesarean section prior to term is attributable to a low tolerance for fetal risks has to be evaluated in further studies.

Moreover, women who delivered preterm tended to have lower CD4 + cell counts. It has already been described that low maternal CD4 + cell count better predicts preterm delivery than viral load [22]. Also, Townsend et al. showed an association between low maternal $\mathrm{CD} 4+$ cell count $(<500$ cells $/ \mu \mathrm{L})$ and prematurity $(13.4 \%$ vs. $10.1 \%, \mathrm{P}=$
0.02) [31]. If cART is begun and viral load is undetectable during pregnancy, spontaneous delivery is now proposed and AZT is not recommended for peripartum use.

Therefore, in future studies it will be important to evaluate the influence of vaginal delivery and new antiretroviral drug regimens on pregnancy outcome.

The strength of our study is the combination of detailed information on pregnancy and delivery with prepregnancy information from the SHCS. The SHCS is a large cohort that includes $40 \%$ of all patients with HIV living in Switzerland and about $70 \%$ of those with AIDS [16, 34]. Since the majority of pregnant women are also included in the MoCHiV [15] the results are likely to be representative of all HIV infected women in Switzerland.

The limitations of these data are that the overall numbers are still small and the power of the study is limited. In addition, no comparison with HIV negative women was performed. The CDC stadium and nadir of CD4 cells were not included in the analyses.

We conclude that early prenatal or prepregnancy identification of HIV infected women remains an essential goal in the prevention of risky conception and adverse pregnancy outcome. Our results emphasize the importance of recommending an HIV test before conception and routinely performing the test in the first trimester in order to avoid missing the diagnosis during pregnancy. Our data provide reassurance that the risks of adverse outcomes of pregnancy attributable to ART are low and likely outweighed by the known benefits of such therapy during pregnancy, with the exception of preterm delivery. Our results indicate that HIV positive women, especially at advanced maternal age and with lower CD4 counts should be monitored carefully in an interdisciplinary setting during pregnancy and observed closely for signs of preterm delivery.

\section{Acknowledgements}

The members of the Swiss HIV Cohort Study and the Swiss Mother and Child HIV Study are: Aebi C, Battegay M, Bernasconi E, Böni J, Brazzola P, Bucher HC, Bürgisser P, Calmy A, Cattacin S, Cavassini M, Cheseaux JJ, Drack G, Dubs R, Egger M, Elzi L, Fischer M, Flepp M, Fontana A, Francioli P (President of the SHCS), Furrer H, Fux CA, Gayet-Ageron A, Gerber S, Gorgievski M, Grawe C, Günthard HF, Gyr T, Hirsch HH, Hirschel B, Hösli I, Kaiser L, Kahlert C, Karrer U, Kind C, Klimkait T, Ledergerber B, Martinetti G, Müller N, Nadal D, Paccaud F, Pantaleo G, Raio L, Rauch A, Regenass S, Rickenbach M, Rudin C (Chairman of the MoChiV Substudy), Schmid P, Schultze D, Schöni-Affolter F, Schüpbach J, Speck R, Martinez de Tejada B, Taffé P, Telenti A, Trkola A, Vernazza P, Weber R, Wyler CA and Yerly S.

\section{References}

[1] Agangi A, Thorne C, Newell ML, European Collaborative Study. Increasing likelihood of further live births in HIVinfected women in recent years. Br J Obstet Gynaecol. 2005;112:881-8. 
[2] Berkowitz GS, Skovron ML, Lapinski RH, Berkowitz RL. Delayed childbearing and the outcome of pregnancy. N Engl J Med. 1990;322:659-64.

[3] Boer K, Nellen JF, Patel D, Timmermans S, Tempelman C, Wibaut $\mathrm{M}$, et al. The AmRo study: pregnancy outcome in HIV-1-infected women under effective highly active antiretroviral therapy and a policy of vaginal delivery. Br J Obstet Gynaecol. 2007;114:148-55.

[4] Brocklehurst P, French R. The association between maternal HIV infection and perinatal outcome: a systematic review of the literature and meta-analysis. $\mathrm{Br} \mathrm{J}$ Obstet Gynaecol. 1998;105:836-48.

[5] Cooper ER, Charurat M, Burns DN, Blattner W, Hoff R. Trends in antiretroviral therapy and mother-infant transmission of HIV. J Acquir Immune Defic Syndr. 2000;24:45-7.

[6] Damus K. Prevention of preterm birth: a renewed national priority. Curr Opin Obstet Gynecol. 2008;20:590-6.

[7] ECS and Swiss Cohort and European Collaborative Study and the Swiss HIV Pregnancy Cohort. Combination antiretroviral therapy and duration of pregnancy. AIDS. 2000;14:2913-20.

[8] Ellis J, Williams H, Graves W, Lindsay MK. Human immunodeficiency virus infection is a risk factor for adverse perinatal outcome. Am J Obstet Gynecol. 2002;186:903-6.

[9] European Collaborative Study. Increased risk of adverse pregnancy outcomes in HIV-infected women treated with highly active antiretroviral therapy in Europe. AIDS. 2004;18: 2337-9.

[10] European Collaborative Study. Mother-to child transmission in the era of highly active antiretroviral therapy. Clin Infect Dis. 2005;40:458-65.

[11] European Collaborative Study. The mother-to-child HIV transmission epidemic in Europe: evolving in the East and established in the West. AIDS. 2006;20:1419-27.

[12] Gilling-Smith C, Nicopoullos JD, Semprini AE, Frodsham LC. HIV and reproductive care - a review of current practice. Br J Obstet Gynaecol. 2006;113:869-78.

[13] Grosch-Woerner I, Puch K, Maier RF, Niehues T, Notheis G, Patel D, et al., for the Multicenter Interdisciplinary Study Group Germany Austria. Increased rate of prematurity associated with antenatal antiretroviral therapy in a German/Austrian cohort of IV-1-infected women. HIV Medicine. 2008;9: 6-13.

[14] Kaaja RJ, Greer IA. Manifestations of chronic disease during pregnancy. J Am Med Assoc. 2005;294:2751-7.

[15] Keiser O, Gayet-Ageron A, Rudin C, Brinkhof MW, Gremlich E, Wunder D, et al., Swiss HIV Cohort Study (SHCS), Swiss Mother \& Child HIV Cohort Study (MoCHiV). Antiretroviral treatment during pregnancy. AIDS. 2008;22:2323.

[16] Ledergerber B, von Overbeck J, Egger M, Lüthy R. The Swiss HIV Cohort Study: rationale, organization and selected baseline characteristics. Soz Praventivmed. 1994;39:387-94.

[17] Leung TY, Leung TN, Sahota DS, Chan OK, Chan LW, Fung TY, et al. Trends in maternal obesity and associated risks of adverse pregnancy outcomes in a population of Chinese women. Br J Obstet Gynaecol. 2008;115:1529-37.

[18] Lorenzi P, Spicher VM, Laubereau B, Hirschel B, Kind C, Rudin $\mathrm{C}$, et al. Antiretroviral therapies in pregnancy: maternal, fetal and neonatal effects. Swiss HIV Cohort Study, the Swiss Collaborative HIV and Pregnancy Study, and the Swiss Neonatal HIV Study. AIDS. 1998;12:F241-7.

[19] Martí C, Peña JM, Bates I, Madero R, de José I, Pallardo LF, et al. Obstetric and perinatal complications in HIV-infected women. Analysis of a cohort of 167 pregnancies between
1997 and 2003. Acta Obstet Gynecol Scand. 2007;86:40915.

[20] Montan S. Increased risk in the elderly parturient. Curr Opin Obstet Gynecol. 2007;19:110-2. Review.

[21] Nesin M. Genetic basis of preterm birth. Front Biosci. 2007;12:115-24. Review.

[22] Newell ML, Dunn DT, Peckham CS, Semprini AE, Pardi G. Vertical transmission of HIV-1: maternal immune status and obstetric factors. The European Collaborative Study. AIDS. 1996;10:1675-81.

[23] Prysak M, Lorenz RP, Kisly A. Pregnancy outcome in nulliparous women 35 years and older. Obstet Gynecol. 1995;85: 65-70. Prysak.

[24] Recommendations of the FKT about pregnancy 2009 (French version). BU05_09f_69-75: update of the special commissions on "HIV/AIDS Clinical and Treatment" (FKT) about HIV, pregnancy and birth. This document exists in French and German only. http://www.bag.admin.ch/hiv_aids.

[25] Rozenbaum MH, Verweel G, Folkerts DK, Dronkers F, van den Hoek JA, Hartwig NG, et al. Cost-effectiveness estimates for antenatal HIV testing in the Netherlands. Int J STD AIDS. 2008;19:668-75.

[26] Sanders LB. Sexual behaviors and practices of women living with HIV in relation to pregnancy. J Assoc Nurses AIDS Care. 2009;20:62-8.

[27] Sibai BM, Gordon T, Thom E, Caritis SN, Klebanoff M, McNellis D, et al. Risk factors for preeclampsia in healthy nulliparous women: a prospective multicenter study. The National Institute of Child Health and Human Development Network of Maternal-Fetal Medicine Units. Am J Obstet Gynecol. 1995;172(2 Pt 1):642-8.

[28] Siega-Riz AM, Siega-Riz AM, Laraia B. The implications of maternal overweight and obesity on the course of pregnancy and birth outcomes. Matern Child Health J. 2006;10(5 Suppl): S153-6.

[29] Suy A, Martinez E, Coll O, Lonca M, Palacio M, de Lazzari $\mathrm{E}$, et al. Increased risk of pre-eclampsia and fetal death in HIV-infected pregnant women receiving highly active antiretroviral therapy. AIDS. 2006;20:59-66.

[30] Szyld EG, Warley EM, Freimanis L, Gonin R, Cahn PE, Calvet GA, et al., NISDI Perinatal Study Group. Maternal antiretroviral drugs during pregnancy and infant low birth weight and preterm birth. AIDS. 2006;20:2345-53.

[31] Townsend CL, Cortina-Borja M, Peckham CS, Tookey PA. Antiretroviral therapy and premature delivery in diagnosed HIV infected women in the United Kingdom and Ireland. AIDS. 2007;21:1019-26.

[32] Tse KY, Ho LF, Lao T. The impact of maternal HBsAg carrier status on pregnancy outcomes: a case-control study. J Hepatol. 2005;43:771-5. Epub 2005 Jun 29.

[33] UNAIDS: 2008 Report on the global AIDS epidemic. http:// www.unaids.org/en/KnowledgeCentre/HIVData/GlobalReport/ 2008/2008_Global_report.asp.

[34] Zwahlen M, Gebhardt M, Rickenbach M, Egger M. [The Swiss HIV Cohort Study - resource for epidemiology and public health] [Article in German]. Ther Umsch. 2004; 61:593-8.

The authors stated that there are no conflicts of interest regarding the publication of this article.

Received August 12, 2009. Revised November 23, 2009. Accepted December 15, 2009. Previously published online February 25, 2010. 